\title{
The Mediating Effect of Self-Regulation on the Association Between Growth Mindset About Work and Living a Calling Among Primary and Secondary School Teachers
}

\author{
Leigang Zhang $\mathbb{D}^{1,2}$ \\ Yuzhu Zhang ${ }^{1,3}$
}

'School of Psychology, Inner Mongolia Normal University, Hohhot, Inner Mongolia Autonomous Region, People's Republic of China; ${ }^{2}$ School of Teacher Education, Shaoxing University, Shaoxing, Zhejiang Province, People's Republic of China; ${ }^{3}$ Hohhot Vocational College, Hohhot, Inner Mongolia Autonomous Region, People's Republic of China
Correspondence: Yuzhu Zhang Hohhot Vocational College, Provincial Highway I0I, Saihan District, Hohhot, Inner Mongolia Autonomous Region, 0I005I, People's Republic of China Email nsdzyz@I63.com
Purpose: Given that extensive studies have documented the wide-ranging benefits of living a calling, determining whether and how living a calling can be improved is of great importance. Although recent research implies that a growth mindset about work may link to self-regulatory processes and living a calling, little research to date has directly examined the relationships between these variables. Building on Burnette's SOMA model, this study was designed to examine the premise that a growth mindset about work was a predictor of living a calling and to explore the mediating role of self-regulation in the growth mindset about work-living a calling link.

Methods: This cross-sectional study was conducted among educational professionals in China. Data were collected from 608 primary and secondary school teachers on growth mindsets about work, self-regulation and living a calling. A structural equation model was used to test the hypothesis that self-regulation would mediate the relationship between a growth mindset about work and living a calling.

Results: Consistent with our premise, a growth mindset about work was positively associated with living a calling. Also, a growth mindset about work was significantly associated with self-regulation strategies in terms of goal setting, perseverance, decision making, and learning from mistakes. As hypothesized, a growth mindset about work was related to higher levels of living a calling via goal setting, perseverance, and learning from mistakes.

Conclusion: The findings contribute to the increasing breadth of the growth mindset literature across various contexts and its consequences for one's living a calling, which expand the nomological web of correlates of growth mindset about work. Furthermore, these findings suggest that fostering a growth mindset about work may facilitate adaptive behaviors and, thereby, serve as a calling intervention.

Keywords: growth mindset about work, self-regulation, living a calling, SOMA model

\section{Introduction}

During the last two decades, the concept of career calling has been an important topic within vocational psychology due to its positive effects on career-specific constructs, such as career preparation, ${ }^{1,2}$ career adaptability, ${ }^{3}$ career commitment, ${ }^{4}$ vocational identity, ${ }^{5}$ job crafting, ${ }^{6}$ and career satisfaction. ${ }^{7}$ Most importantly, career calling can alleviate the negative effects of work stress and burnout on well-being, ${ }^{8}$ motivate employees to fully engage in work and derive meaning from work. ${ }^{9}$ Specific to the teaching profession, a sense of calling is considered as an important 
motivational factor for teachers. It is widely recognized that those who view teaching as their calling are likely to be more enthusiastic and motivated toward their work, and are more willing to accept the extra duties that often accompany the teacher's role. ${ }^{10}$ Additionally, such teachers feel that their work has a positive effect on their students or on society in general. In China, research on calling is still at an early stage. Several empirical studies have demonstrated that career calling is positively related to job performance and work well-being of Chinese teachers. $^{11,12}$

The concept of career calling within occupational and counseling psychology has been acknowledged and discussed for several decades. For example, Dobrow and TostiKharas defined calling as "a consuming, meaningful passion people experience toward a domain". ${ }^{13}$ Dik and Duffy viewed calling as "a transcendent summons to a meaningful career that is used to serve others". ${ }^{14}$ Regardless of the specific definition, a calling represents a career that is personally meaningful and prosocial in nature, which is clearly distinguished from other related work constructs, such as work engagement and commitment. ${ }^{14}$ For example, teacher candidates often report that their career choices stem from a desire to create a better future or society. Although research with samples of diverse working adults has reported that more than $50 \%$ of this population may experience a calling, ${ }^{15}$ only a portion can actually pursue and actualize their calling in their current careers. It does mean that having a calling is not necessarily synonymous with living a calling. Thus, a particularly important distinction has to be made between having and living a calling. ${ }^{16}$ Roughly, having a calling refers to the degree to which an individual believes she or he is called to a particular line of work, whereas living a calling refers to the degree to which one is currently living their calling. A growing number of studies have found that living a calling is more strongly associated with well-being than does having a calling. ${ }^{17,18}$ Furthermore, relative to living a calling, having a calling is not always sufficient to yield positive work and life outcomes. ${ }^{19}$ Taken together, the positive effects of having a calling may be contingent upon whether a person is able to actually live it. Considering that living a calling underlies the benefits of a calling, it would be of great value to identify individual and organizational factors that allow people to successfully live their calling.
The majority of research on living a calling has almost exclusively been concerned with assessing the variables that account for the linkage between having a calling and living a calling. ${ }^{20,21}$ Also, although research has recently started to investigate determinants of living a calling, most existing studies have focused primarily on contextual factors. ${ }^{22,23}$ Recent research has demonstrated that individuals with lower socioeconomic status are just as likely as others to have a calling, but are less likely to successfully live their calling, as they have restricted access to vocational opportunity that decreases their ability to feel a sense of work meaning and work volition in pursuing a career path. In contrast, individuals from higher social status backgrounds are more likely to experience higher feelings of living a calling, as they can concentrate more on higher order needs at work, ${ }^{24}$ and sense more autonomous and fulfilling work. ${ }^{25}$ However, extant research on the antecedents of living a calling mainly considers individuals as passive occupants of the jobs, ${ }^{26}$ and neglect the fact that personal agency is essential to objective and subjective career success. ${ }^{27}$ In addition, since social status is more stable and impossible to change in the short term, future study on factors of living a calling should focus on positive psychological traits, which can be fostered through intervention. Therefore, this study aimed to examine the relationship between a growth mindset about work and living a calling, and account for the mediating role of self-regulation. The SOMA model (setting, operating, monitoring, and achieve) was used as a framework. ${ }^{28}$ In this model, self-regulation has been identified as a potential mediating factor that explains the psychological processes underlying the relationship between a growth mindset and goal achievement. Figure 1 shows the hypothetical mediation model.

\section{Theory and Hypothesis}

\section{Growth Mindset About Work and Living} a Calling

Mindset theory, ${ }^{29,30}$ rooted in implicit theories, ${ }^{31,32}$ assumes that individuals vary in their beliefs about the stability of human characteristics, such as intelligence, ${ }^{33}$ personality, ${ }^{34}$ and creativity. ${ }^{35}$ Some people endorsing a growth mindset believe that characteristics are malleable and can be cultivated or developed, whereas others endorsing a fixed mindset believe that such characteristics are stable. ${ }^{36}$ Mindsets are at the core of people's meaning systems, ${ }^{37}$ the cognitive structures that shape how people 


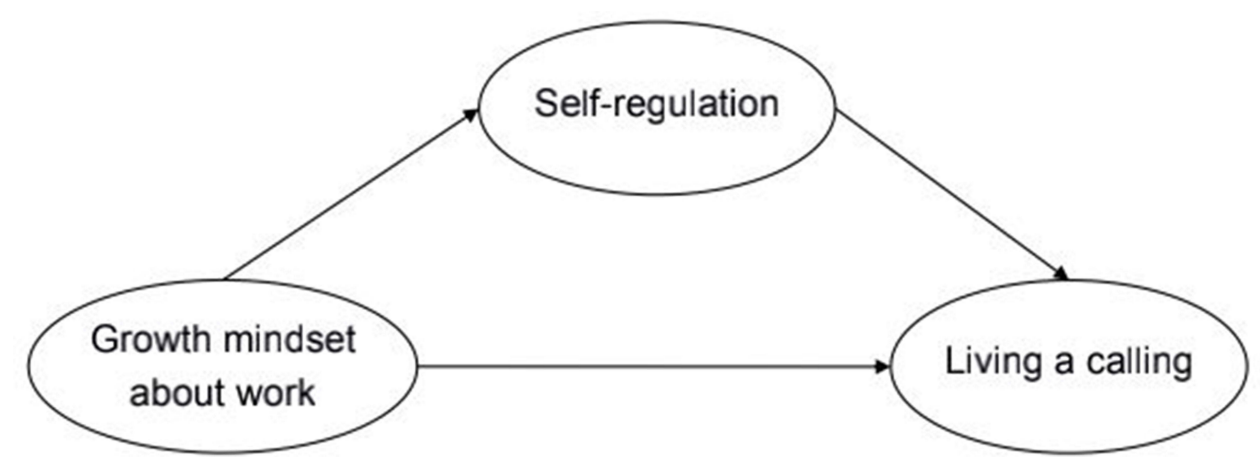

Figure I Proposed structural model.

interpret efforts, construct explanations, form expectations, and guide action in response to different objects and events, particularly during challenging circumstances. In particular, a growth mindset helps people free themselves from concerns about their current abilities, and motivates them to seek learning opportunities to develop new skills. $^{38,39}$ Interestingly, it is possible to shift from a fixed to a growth mindset. Although the concept of mindsets is well-studied in the education literature, the idea of a growth mindset is less represented in human resource development scholarly literature. As Burnette et al. suggest, individuals may believe that there are a limited number of careers that would be well-matched (i.e. fixed mindset about work), or that careers develop by overcoming challenges and obstacles (i.e. growth mindset about work). ${ }^{40}$ Previous studies have linked the growth mindset with various positive effects in workplaces, such as increased work engagement, productivity and creativity in organizations. ${ }^{41}$ Essentially, a growth mindset about work represents confidence and personal agency in the personal growth and career development. Consequently, given the large body of research presented above and, specifically, the work of Burnette et al., we expect that employees' growth mindsets about work may influence their living a calling.

Researchers generally agree on the long-term nature of calling instead of the episodic duration of work engagement or experience of "flow". 42 Hall and Chandler viewed the development of the career calling "as an ongoing, cyclical process, involving deep exploration of personal goals, trial efforts, and reflection on success". 43 According to the view of Hall and Chandler, living a calling therefore can be illustrated as a sense of meaningful work experiences that emerges when people are able to engage in fulfilling work. In other words, it may represent a form of optimal experience. Conceptualized as personally fulfilling, living a calling predicts or causes greater achievement and fulfillment of potential. However, due to diverse financial, structural, and social constraints, which hinder people from realizing their occupational aspirations and limit their work volition, some people are unable to choose desired jobs or careers that are in line with their interests or preferences. ${ }^{44}$ Thus, these people who do have a strong calling are unable to live their calling. Nevertheless, living out a calling can be experienced if people exert more effort on tasks, strengthen psychological commitment toward their career, ${ }^{22}$ and engage in adaptive self-regulatory strategies. Although there is no direct evidence provided to support the link between a growth mindset and living a calling, we speculate that a growth mindset about work may have the potential to foster living a calling, as a growth mindset that a job is mutable leads to a range of adaptive responses within the career domain. ${ }^{45}$ For example, a growth mindset helps people stay focused on their goals, ${ }^{46}$ and influences individuals' strategies which they have used to cope with the barriers encountered in implementing their goals and the ways in which they seek and do their jobs. ${ }^{47}$

Growth mindset about work can be conceived of as a psychological strength that manifests as personal agency in career development. It plays a critical role in energizing the problem-solving process and continued goal pursuit when faced with challenges. Once individuals choose and begin to establish a goal, their growth mindset elicits increased perceptions of control over attaining the goal, which allows individuals to fully commit themselves to long-term developmental goals. Conversely, fixed mindset impedes individuals' task progress. Extant literature has demonstrated that a growth mindset can facilitate work engagement $^{48,49}$ and feedback-seeking behavior. $^{50}$ 
Individuals endorsing a growth mindset are sensitive to probability of success, have higher levels of desires for advancement and accomplishment, and can better understand the best direction to focus their career development because they believe a successful career can be achieved through hard work. Consequently, they are likely to redouble and optimize their efforts to minimize the discrepancy between current performance and future goals, and move closer to desired goals, ultimately experiencing a sense of meaning in their work. Additionally, it is important to note that growth mindset relates to increased job satisfaction. ${ }^{51}$ When employees derive high meaning and deep enjoyment from their work, they will experience more living a calling. In sum, individuals who endorse the belief that a successful career can be developed and that they can achieve their future career goals are more likely to feel they are actually living out their calling than those who believe careers are destined.

Hypothesis 1: Growth mindset about work is positively related to living a calling.

\section{Growth Mindset About Work and Self-Regulation}

Self-regulation, defined as "a highly adaptive, distinctively human trait that enables people to override and alter their responses", 52 exists in a remarkably broad range of challenging behaviors across a wide variety of contexts. Selfregulation is a multifaceted process, consisting of three integral components of processes: goal setting entails formulating plans, goals or standards, goal operating involves a range of goal-oriented actions, and goal monitoring refers to a consideration of potential obstacles and available resources for achieving success. ${ }^{28}$ According to Carver and Scheier, ${ }^{53}$ who conceptualized self-regulation as goaldirected and feedback-controlled behaviors, self-regulation is an important process in cognitive control theory, which highlights the cognitive variables that are assumed to enable people to exercise personal agency in their career development. Growing evidence indicates that people often utilize cognitive, affective, and motivational resources to shape their career development by striving for goals or adjusting their goals. ${ }^{54}$ As a consequence, the concept of selfregulation has received much scholarly attention because it may serve as a mental resource that motives people to sustain effective engagement in particular activities, and drives people to pursue adaptive long-term developmental goals. ${ }^{55}$ Given the importance of self-regulation for successful goal-striving, identifying factors related to better self-regulation is critical, especially when facing setbacks.

Dweck's social-cognitive model of motivation suggests that implicit theories would be associated with an array of self-regulatory processes. $^{56}$ The motivation behind a growth mindset is thought to be mainly intrinsic and enhancement-driven, with an emphasis on mastery and flexibility in responding to and dealing with work-related challenges. However, existing studies have shown that the growth mindset on self-regulatory processes is inconsistent. On the one hand, considerable research demonstrates that individuals holding a growth mindset engage in various motivational and behavioral processes that direct their attention toward meaningful career-related activities, and sustain their perseverance of effort, which results in an increased likelihood of goal success. ${ }^{57,58}$ On the other hand, some studies have shown null effects or negative effects of a growth mindset on self-regulatory processes. ${ }^{59}$ To integrate these mixed findings, Burnette et al. conducted meta-analyses, and found that growth mindset would predict goal setting, goal operating, and goal monitoring. ${ }^{28}$ In particularl, individuals who recognize that ability can be developed over time tend to focus more on learning goals, believe in the utility of effort, and adopt mastery-oriented strategies, ${ }^{60}$ such as learning from mistakes and accepting feedback and criticism. ${ }^{61,62}$ The higher a growth mindset people hold, the more active and effective self-regulatory strategies they use. Also, motivation theories lend support to an important role of a growth mindset in achievement motivation, goal orientation, and self-regulation.Thus, cultivating growth mindsets may function as a promising approach for altering perceptions of effort and enhancing self-regulation. Based on the above arguments, we suggest that individuals who believe a successful career is mostly a matter of learning to grow within the job are characterized by an eagerness to learn and develop themselves, strong self-regulation and a high ability to cope with career barriers.

Hypothesis 2: Growth mindset about work is related to adaptive, mastery-oriented self-regulatory processes.

\section{The Mediating Role of Self-Regulation}

Self-regulation theory is central to the understanding of human behavior, and has been used to illuminate a variety of phenomena in career management. ${ }^{63}$ It addresses the psychological process through which people regulate their cognition, emotions, and actions in career development 
and progress. Self-regulation can be seen as a process of achieving goal results in the face of setbacks that would otherwise prevent achievement of these goals. ${ }^{64}$ Researchers have empirically demonstrated that adaptive self-regulatory processes play an influential role in optimizing the person-job fit, ${ }^{65}$ coping with external constraints, ${ }^{66}$ facilitating progress towards a future career, ${ }^{67}$ and building a satisfactory career path over time. $^{68}$ As such, self-regulation is theorized to be a prerequisite of complex cognitive abilities in humans, and is essential for personal adjustment and achievement. Although the consequences of self-regulation are well established in career literature, there has been little research investigating the link between self-regulation and living a calling.

Some existing research argues that the discrepancy between having a calling and living a calling arises when people fail to freely pursue a specific career that matches with his or her calling due to individual or contextual factors. From a cognitive control theory perspective, the degree of discrepancies between current career choices and idealized career aspirations is dependent on the level of positive career-related activities they are engaging in, such as active career self-regulatory behavior. $^{69}$ For example, seeking career guidance, an example of a self-regulatory strategy, serves as a protective factor in weakening the relationship between career compromise and career distress. ${ }^{70}$ Self-regulation involves the individual's ability to modulate emotions and behaviors in order to accomplish goal-oriented activities, and allow a person to delay gratification in the short term to attain the most desired outcomes. ${ }^{71}$ When people self-regulate, they are guiding or adjusting their behaviors to maintain the agreement between what they are doing and what they intend and would like to do. Thus, the logical nexus between self-regulation and living a calling is clear. Previous research demonstrated that self-regulation was positively associated with volition and commitment, ${ }^{72}$ which are causal predictors of living a calling. Overall, as an adaptive human ability, selfregulation would predict increased levels of living a calling. Specifically, individuals with higher selfregulation ability tend to exert more effort into work, persist in the face of constraints, and manage their own career in the desired direction, thus resulting in higher levels of living a calling. Based on a review of prior literature, a positive relationship between self-regulation and living a calling can be expected.
Hypothesis 3: Self-regulation is positively related to living a calling.

Research has begun to examine the underlying processes that can explain the positive relation between a growth mindset and goal achievements. For example, the SOMA model has been recently developed to better understand how a growth mindset influences goal achievement. $^{28}$ This model synthesizes implicit theories and self-control theory, and stresses the motivational and effortful control processes underlying the relationship between a growth mindset and goal achievement. Within this theoretical model, a growth mindset as a motivational construct predicts self-regulatory processes in terms of goal setting, goal operation, and goal monitoring, which contribute to goal achievement. According to the SOMA model, and taking into consideration the study carried out by Praskova et al. who observed a positive relationship between a calling and self-regulatory processes, ${ }^{73}$ we expect the employees with a growth mindset about work to engage in active self-regulatory strategies, such as pursuing learning goals and adopting mastery-oriented strategies. These self-regulatory strategies, in turn, shape adapting behaviors to live a calling out. In short, a growth mindset about work can influence one's living a calling via influencing the self-regulatory strategies. Thus, we draw upon the SOMA model as an overarching framework to theorize the mediating role of self-regulation in the relationship between a growth mindset about work and living a calling.

Hypothesis 4: Self-regulation mediates the relationship between a growth mindset about work and living a calling.

\section{Materials and Methods Procedure and Participants}

This study used survey data that were collected from a convenience sample of 12 primary and secondary schools in Zhejiang Province, China. With the assistance of the local education authorities, teachers were invited to complete an online survey. A total of 650 teachers voluntarily participated in this study. At the start of the study, teachers were informed about the aims of this study and the anonymity of their participation. They were then asked to fill out the self-reported questionnaires. They did not receive any compensation for their participation. Due to improper completion, 42 copies were discarded, yielding a final sample of 608 participants for data 
analysis. The sample ranged in age from 25 to 58 years with mean age of 35.62 years $(\mathrm{SD}=11.57)$. In terms of the educational level, 173 teachers were below a Bachelor's degree (28.45\%), 422 teachers attained a bachelor's degree (69.41\%), only 13 teachers obtained a Master's degree (2.14\%). This study was approved by the Shaoxing university ethics committee.

\section{Measurement}

The questionnaire was constructed to assess growth mindsets about work, self-regulation, and living a calling along with several control variables. As questionnaires were originally constructed in English, we created Chinese versions using a back-translation procedure recommended by Brislin. ${ }^{74}$ First, a translation into Chinese was made by a native Chinese scholar who is fluent in English and then a back-translation into English was made by a English researcher with excellent knowledge of Chinese. This procedure ensures that the translated survey items precisely transmitted the meaning of the original English version. All items were scored on a 5-point Likert-type scale ranging from 1 (strongly disagree) to 5 (strongly agree), with higher scores reflecting higher levels of the construct. All items for the three constructs are shown in Table 1.

\section{Implicit Theory of Work Scale (ITWS)}

The 5-item Implicit Theory of Work Scale (ITWS), adapted by Burnette and Pollack, ${ }^{40}$ was administered to measure the growth mindset about work. A sample item is "A successful career is mostly a matter of learning to grow within the job". In this study, Cronbach's alpha was 0.83 .

\section{Short Version of Self-Regulation Questionnaire (SV-SRQ)}

The Short Version of Self-Regulation Questionnaire (SVSRQ), adapted by Pichardo et al. ${ }^{75}$ was used to assess participants' ability to regulate their behaviors in order to achieve desired future outcomes. It is a 17-item scale which consists of four subscales: goal setting (six items; e.g., "I set goals for myself and keep track of my progress"), perseverance (three items; e.g., "I have a lot of willpower"), decision making (five items; e.g., "I have trouble making up my mind about things"), and learning from mistakes (three items; e.g., "I learn from my mistakes"). Some items were reverse-coded to be in the positive direction. In our sample, the Cronbach's alpha of the four subscales were 0.89 for goal setting, 0.86 for perseverance, 0.87 for decision making, and 0.82 for learning from mistakes.

\section{Living a Calling Scale (LCS)}

The 6-item Living a Calling Scale (LCS), developed by Duffy et al. ${ }^{17}$ was used to assess participants' current levels of living a calling. A sample item is "I have regular opportunities to live out my calling". Cronbach's alpha for the scale was 0.88 in our sample.

\section{Control Variables}

Demographic characteristics including age, gender, educational level, tenure were used as control variables, because these variables were found to influence living a calling. ${ }^{17}$ They were collected using the following single items: "What is your age?", "What is your gender?", "What is your highest level of education?", and "How long have you worked in this school".

\section{Statistical Analysis}

The IBM SPSS Statistics 25.0 and AMOS 20.0 were used to test the reliability and validity of measurements, and the hypothesized model. First, confirmatory factor analysis (CFA) using maximum likelihood estimation was conducted to test the construct validity of the Chinese versions of all scales. Additionally, the average variance extracted (AVE) and construct reliability (CR) were calculated to provide evidence of convergent validity, which should be higher than 0.50 and 0.70 respectively. Cronbach's alpha was calculated as measure of reliability. The measurement model was assessed to ensure all latent variables were independent. Parcels rather than individual items were used as indicators of the latent variables by following the parceling procedure that averaged lower loaded items with higher loaded ones. ${ }^{76}$ The advantages of item parceling comprise stronger model fit and fewer parameters. Model fit was assessed with the comparative fit index (CFI), Tucker-Lewis index (TLI), root mean squared error of approximation (RMSEA), and standardized root mean squared residual (SRMR). CFI and TLI values greater than 0.90 , RMSEA values below 0.06 , and SRMR values below 0.08 indicate good model fit. ${ }^{77}$

Then, the common method variance (CMV) was estimated using Harman's one-factor test. Pearson correlation analysis was conducted to examine the relationships between growth mindsets about work, self-regulation, and living a calling. Third, structural equation modeling (SEM) was conducted to 
Table I Items and Standardized Factor Loading Scores for Confirmatory Factor Analysis, Cronbach $\alpha$, CR and AVE

\begin{tabular}{|c|c|c|c|c|c|}
\hline & & $\begin{array}{l}\text { Factor } \\
\text { Loadings }\end{array}$ & Cronbach $\alpha$ & CR & AVE \\
\hline \multirow{5}{*}{$\begin{array}{l}\text { Growth mindset about } \\
\text { work }\end{array}$} & The ideal career develops gradually over time. & 0.75 & \multirow[t]{5}{*}{0.83} & \multirow[t]{5}{*}{0.89} & \multirow[t]{5}{*}{0.54} \\
\hline & $\begin{array}{l}\text { A successful career evolves through hard work and resolution of } \\
\text { incompatibilities. }\end{array}$ & 0.74 & & & \\
\hline & $\begin{array}{l}\text { A successful career is mostly a matter of learning to grow within the } \\
\text { job. }\end{array}$ & 0.71 & & & \\
\hline & $\begin{array}{l}\text { Challenges and obstacles in a career can make employees even } \\
\text { stronger. }\end{array}$ & 0.70 & & & \\
\hline & It takes a lot of time and effort to cultivate a good career. & 0.76 & & & \\
\hline \multirow{7}{*}{$\begin{array}{l}\text { Self-Regulation } \\
\text { Goal setting }\end{array}$} & & & \multirow{7}{*}{0.89} & \multirow{7}{*}{0.92} & \multirow{7}{*}{0.58} \\
\hline & I set goals for myself and keep track of my progress. & 0.78 & & & \\
\hline & Once I have a goal, I can usually plan how to reach it. & 0.73 & & & \\
\hline & $\begin{array}{l}\text { If I make a resolution to change something, I pay a lot of attention to } \\
\text { how I am doing. }\end{array}$ & 0.76 & & & \\
\hline & I have a hard time setting goals for myself. & 0.74 & & & \\
\hline & I usually keep track of my progress toward my goals. & 0.81 & & & \\
\hline & I have trouble making plans to help me reach my goals. & 0.79 & & & \\
\hline \multirow[t]{3}{*}{ Perseverance } & I have a lot of willpower. & 0.72 & \multirow[t]{3}{*}{0.86} & \multirow[t]{3}{*}{0.90} & \multirow[t]{3}{*}{0.54} \\
\hline & I get easily distracted from my plans. & 0.77 & & & \\
\hline & I am able to resist temptation & 0.71 & & & \\
\hline \multirow[t]{5}{*}{ Decision making } & I have trouble making up my mind about things. & 0.70 & \multirow[t]{5}{*}{0.87} & \multirow[t]{5}{*}{0.89} & \multirow[t]{5}{*}{0.55} \\
\hline & I put off making decisions. & 0.86 & & & \\
\hline & $\begin{array}{l}\text { When it comes to deciding about a change, I feel overwhelmed by the } \\
\text { choice. }\end{array}$ & 0.72 & & & \\
\hline & Little problems or distractions throw me off course. & 0.70 & & & \\
\hline & I have so many plans that it's hard for me to focus on any one of them. & 0.72 & & & \\
\hline \multirow[t]{3}{*}{ Learning from mistakes } & I do not seem to learn from my mistakes. & 0.78 & \multirow[t]{3}{*}{0.82} & \multirow[t]{3}{*}{0.93} & \multirow[t]{3}{*}{0.57} \\
\hline & $\begin{array}{l}\text { I usually only have to make a mistake one time in order to learn from } \\
\text { it. }\end{array}$ & 0.76 & & & \\
\hline & I learn from my mistakes. & 0.72 & & & \\
\hline \multirow[t]{6}{*}{ Living a calling } & I have regular opportunities to live out my calling. & 0.89 & \multirow[t]{6}{*}{0.88} & \multirow[t]{6}{*}{0.95} & \multirow[t]{6}{*}{0.76} \\
\hline & I am currently working in a job that closely aligns with my calling. & 0.84 & & & \\
\hline & I am consistently living out my calling. & 0.91 & & & \\
\hline & I am currently engaging in activities that align with my calling. & 0.86 & & & \\
\hline & I am living out my calling right now in my job. & 0.84 & & & \\
\hline & I am working in the job to which I feel called. & 0.90 & & & \\
\hline
\end{tabular}

Abbreviations: $C R$, construct reliability; AVE, average variance extracted. 
assess the hypothesized structural model. For the mediation analysis, we applied 2000 bootstrap iterations for an additional test of significance using the Preacher and Hayes multiple mediation macro. ${ }^{78} 95 \%$ bias-corrected bootstrap confidence intervals for the indirect effects were computed. If zero is not included in the range of the $95 \%$ confidence intervals, the mediation is statistically significant at the $\mathrm{p}<0.05$ level.

\section{Results}

\section{Reliability and Validity of the Measurement}

Prior to testing the hypothesized structural model, the Chinese versions of implicit theory of work, selfregulation, and living a calling scale were validated to ensure that they were psychometrically sound. A series of confirmatory factor analyses using maximum likelihood estimation were conducted to examine the construct validity of each measurement. The results showed that the 17item four-factor model of self-regulation was a good fit $\left(\chi^{2} / \mathrm{df}=2.39, \mathrm{CFI}=0.96, \mathrm{TLI}=0.95, \mathrm{RMSEA}=0.07\right.$, SRMR $=0.05$ ), with the CFI and TLI approaching 0.90 , and RMSEA meeting the criterion of 0.08 . To establish that the four-factor model is more suitable than alternative factor structures, we conducted a comparison with a onefactor model, where all items loaded on a single factor. As expected, the one-factor model $\left(\chi^{2} / \mathrm{df}=5.51, \mathrm{CFI}=0.73\right.$, $\mathrm{TLI}=0.71, \mathrm{RMSEA}=0.14, \mathrm{SRMR}=0.12$ ) fitted the data significantly worse than the four-factor model. In a similar vein, a growth mindset about work was confirmed as a one-factor construct with five items $(\chi 2 / \mathrm{df}=2.97, \mathrm{CFI}$ $=0.96$, TLI $=0.95$, RMSEA $=0.06$, SRMR $=0.05)$. Living a calling was demonstrated as a one-factor construct with six items $\left(\chi^{2} / \mathrm{df}=1.63, \mathrm{CFI}=0.97, \mathrm{TLI}=0.95\right.$, $\mathrm{RMSEA}=0.06, \mathrm{SRMR}=0.05)$. All factor loadings ranged from 0.70 to 0.86 , and were statistically significant.

To provide further evidence for the convergent validity of our measurements, we examined each factor's composite reliability (CR) and average variance extracted (AVE). The CFA factor loadings, Cronbach's alphas, CR and AVE are presented in Table 1. All the constructs exhibited CR values above 0.7 , ranging from 0.89 to 0.95 . All the AVE scores were above 0.50 , providing evidence of good convergent validity. Cronbach's alphas of all factors ranged from 0.83 to 0.89 , showing good internal consistency. In sum, these analyses supported the reliability and validity of the constructs.

\section{Measurement Model Testing}

Discriminant validity was assessed by conducting CFA to compare measurement models. As recommended by Weston and Gore, ${ }^{76}$ we used item parcels as indicators of constructs that were assessed by more than five items. Given that growth mindset, perseverance, decision making, and learning from mistakes have less than five items, their respective items are treated as observed indicators for corresponding latent variable. As both goal setting and living a calling have six items, three item parcels were created for each construct. We compared the proposed sixfactor solution distinguishing between growth mindset, goal setting, perseverance, decision making, learning from mistakes, and living a calling to two alternative models. Specifically, we estimated a one-factor model where all variables were hypothesized to load onto one factor. Next, a two-factor model where items from growth mindset and four self-regulatory strategies were set on a one factor, and living a calling loaded on the second factor. The measurement model showed good fit statistics for the six latent variables $\left(\chi^{2} / \mathrm{df}=2.64, \mathrm{CFI}=0.91, \mathrm{TLI}=\right.$ $0.90, \mathrm{RMSEA}=0.07, \mathrm{SRMR}=0.06$ ), providing evidence of discriminant validity of these variables. Both the onefactor model $\left(\chi^{2} / \mathrm{df}=7.68, \mathrm{CFI}=0.68\right.$, TLI $=0.65$, RMSEA $=0.22$, SRMR $=0.20)$ and the two-factor model $\left(\chi^{2} / \mathrm{df}=4.71, \mathrm{CFI}=0.75, \mathrm{TLI}=0.74, \mathrm{RMSEA}=\right.$ $0.18, \operatorname{SRMR}=0.15)$ did not fit the data well.

\section{Common-Method Bias Test}

We used Harman's single factor method to estimate common method variance in the present study. The result revealed that the first factor accounted for $32.69 \%$ of variances, which was less than $50 \%$ of variance, ${ }^{79}$ indicating that there was no obvious common-method bias in this study.

\section{Descriptive Statistics and Correlation Analysis}

The scores of growth mindsets about work, self-regulation, and living a calling were compared with demographic characteristics of the participants. Table 2 shows the results of the independent-samples $t$-test and one-way ANOVAs, and Table 3 presents correlations of the study constructs. Growth mindset about work was positively related to four self-regulation strategies $(r=0.39$, $\mathrm{p}<0.01$ for goal setting; $\mathrm{r}=0.58, \mathrm{p}<0.01$ for perseverance; $\mathrm{r}=0.59, \mathrm{p}<0.01$ for decision making; $\mathrm{r}=0.40$, 
Table 2 Teachers' Demographics and the Level of Growth Mindset About Work, Self-Regulation, and Living a Calling

\begin{tabular}{|c|c|c|c|c|c|c|c|}
\hline Variables & $\mathbf{n}$ & $\begin{array}{l}\text { Growth Mindset About } \\
\text { Work }\end{array}$ & $\begin{array}{l}\text { Goal } \\
\text { Setting }\end{array}$ & Perseverance & $\begin{array}{l}\text { Decision } \\
\text { Making }\end{array}$ & $\begin{array}{l}\text { Learning from } \\
\text { Mistakes }\end{array}$ & $\begin{array}{l}\text { Living } \\
\text { a Calling }\end{array}$ \\
\hline $\begin{array}{l}\text { Gender } \\
\text { Male } \\
\text { Female } \\
\text { t } \\
\text { P }\end{array}$ & $\begin{array}{l}211 \\
397\end{array}$ & $\begin{array}{c}3.46 \pm 0.69 \\
3.30 \pm 0.70 \\
2.73 \\
0.007\end{array}$ & $\begin{array}{c}3.35 \pm 0.55 \\
3.24 \pm 0.53 \\
2.33 \\
0.020\end{array}$ & $\begin{array}{c}3.33 \pm 0.50 \\
3.15 \pm 0.55 \\
4.05 \\
0.000\end{array}$ & $\begin{array}{c}3.18 \pm 0.43 \\
3.04 \pm 0.38 \\
4.01 \\
0.000\end{array}$ & $\begin{array}{c}2.90 \pm 0.68 \\
2.88 \pm 0.61 \\
0.41 \\
0.68\end{array}$ & $\begin{array}{c}3.4 I \pm 0.55 \\
3.35 \pm 0.5 \mathrm{I} \\
\mathrm{I} .34 \\
0.18\end{array}$ \\
\hline $\begin{array}{l}\text { Educational level } \\
\text { Junior college or } \\
\text { lower } \\
\text { Bachelor's degree } \\
\text { Master's degree } \\
\text { F } \\
\text { P }\end{array}$ & $\begin{array}{c}173 \\
422 \\
13\end{array}$ & $\begin{array}{c}3.39 \pm 0.77 \\
3.4 I \pm 0.67 \\
3.48 \pm 0.60 \\
0.12 \\
0.889\end{array}$ & $\begin{array}{c}3.34 \pm 0.57 \\
3.30 \pm 0.54 \\
3.33 \pm 0.41 \\
0.39 \\
0.68\end{array}$ & $\begin{array}{c}3.23 \pm 0.54 \\
3.29 \pm 0.52 \\
3.07 \pm 0.36 \\
1.78 \\
0.17\end{array}$ & $\begin{array}{c}3.07 \pm 0.53 \\
3.16 \pm 0.37 \\
3.05 \pm 0.23 \\
3.10 \\
0.046\end{array}$ & $\begin{array}{c}2.84 \pm 0.67 \\
2.9 I \pm 0.65 \\
2.94 \pm 0.63 \\
0.83 \\
0.44 \mathrm{I}\end{array}$ & $\begin{array}{c}3.30 \pm 0.52 \\
3.42 \pm 0.54 \\
3.57 \pm 0.72 \\
4.09 \\
0.017\end{array}$ \\
\hline $\begin{array}{l}\text { Working years } \\
\text { I-5 years } \\
6-10 \text { years } \\
\text { II-15 years } \\
16-20 \text { years } \\
>21 \text { years } \\
\text { F } \\
\text { P }\end{array}$ & $\begin{array}{l}196 \\
192 \\
113 \\
38 \\
69\end{array}$ & $\begin{array}{c}3.37 \pm 0.62 \\
3.42 \pm 0.76 \\
3.33 \pm 0.71 \\
3.68 \pm 0.70 \\
3.44 \pm 0.64 \\
1.98 \\
0.097\end{array}$ & $\begin{array}{c}3.21 \pm 0.46 \\
3.24 \pm 0.61 \\
3.31 \pm 0.54 \\
3.57 \pm 0.48 \\
3.64 \pm 0.47 \\
11.72 \\
0.000\end{array}$ & $\begin{array}{c}3.23 \pm 0.49 \\
3.26 \pm 0.56 \\
3.24 \pm 0.57 \\
3.29 \pm 0.36 \\
3.43 \pm 0.51 \\
2.05 \\
0.007\end{array}$ & $\begin{array}{c}3.15 \pm 0.44 \\
3.09 \pm 0.43 \\
3.15 \pm 0.36 \\
3.05 \pm 0.37 \\
3.26 \pm 0.37 \\
2.66 \\
0.032\end{array}$ & $\begin{array}{c}2.87 \pm 0.58 \\
2.89 \pm 0.72 \\
2.82 \pm 0.64 \\
3.09 \pm 0.81 \\
2.99 \pm 0.62 \\
1.57 \\
0.18\end{array}$ & $\begin{array}{c}3.30 \pm 0.53 \\
3.38 \pm 0.47 \\
3.47 \pm 0.56 \\
3.28 \pm 0.64 \\
3.63 \pm 0.57 \\
5.81 \\
0.000\end{array}$ \\
\hline
\end{tabular}

Table 3 Pearson Correlations Among the Latent Variables

\begin{tabular}{|l|c|c|c|c|c|}
\hline Variables & I & $\mathbf{2}$ & $\mathbf{3}$ & $\mathbf{4}$ & $\mathbf{5}$ \\
\hline I. Growth mindset & - & & & & \\
about work & & & & & \\
2. Goal setting & $0.39 * *$ & - & & & \\
3. Perseverance & $0.58^{* *}$ & $0.72^{* *}$ & - & & \\
4. Decision making & $0.59 * *$ & $0.6 \mathrm{I}^{* *}$ & $0.70^{* *}$ & - & \\
5. Learning from & $0.49^{* *}$ & $0.5 \mathrm{I}^{* *}$ & $0.54^{* *}$ & $0.63^{* *}$ & - \\
mistakes & & & & & \\
6. Living a calling & $0.50^{* *}$ & $0.49 * *$ & $0.5 \mathrm{I}^{* *}$ & $0.52^{* *}$ & $0.42^{* *}$ \\
\hline
\end{tabular}

Note: $*_{p}<0.01$.

$\mathrm{p}<0.01$ for learning from mistakes), and living a calling ( $\mathrm{r}$ $=0.50, \mathrm{p}<0.01)$. Self-regulation strategies were positively related to living a calling.

\section{Structural Model Testing}

After verifying the measurement model, we analyzed the structural model and tested our hypotheses. Structural equation modeling was conducted using AMOS 20.0 with maximum likelihood estimation to test the hypothesized mediation model in which growth mindset about work was related to living a calling via the four self- regulation strategies (Figure 2). This model also included the direct path from growth mindset about work to living a calling. The hypothesized model was an adequate fit with the data $\left(\chi^{2} / \mathrm{df}=1.88, \mathrm{CFI}=0.96\right.$, TLI $=0.95$, RMSEA $=$ 0.05 , SRMR $=0.05)$. As expected, growth mindset about work was positively related to living a calling $(\beta=0.22$, $p<0.01)$, goal setting $(\beta=0.39, p<0.01)$, perseverance $(\beta=$ $0.58, p<0.01)$, decision making $(\beta=0.59, p<0.01)$, and learning from mistakes $(\beta=0.50, p<0.01)$, supporting hypothesis 1 and 2 . Also, there were significant positive paths from goal setting $(\beta=0.15, p<0.01)$, perseverance $(\beta$ $=0.17, p<0.01)$, and learning from mistakes $(\beta=0.14$, $p<0.01)$ to living a calling; but the path from decision making to living a calling was not significant $(\beta=0.09$, $p>0.05$ ).

To further assess the indirect effects in a multiple mediator model, bootstrapping techniques with 2000 samples was performed using the Preacher and Hayes multiple mediation macro. ${ }^{78} 95 \%$ confidence intervals were calculated for the upper and lower potential limits of these indirect effects. Mediation is indicated if the $95 \%$ confidence intervals for the mediation models do not include zero. As can be seen in Table 4, bootstrap analyses revealed significant indirect effects of a growth mindset 


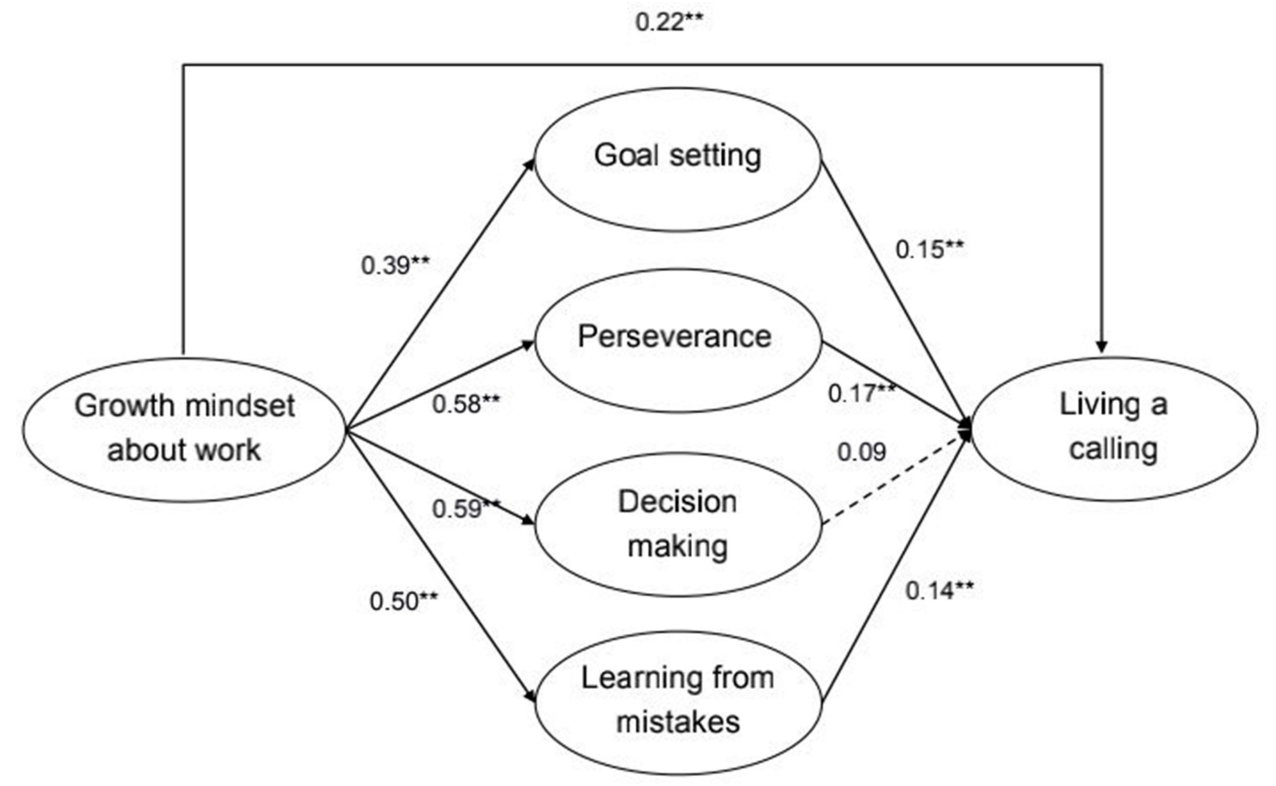

Figure 2 Mediating role of self-regulation in the relationship between growth mindset about work and living a calling.

about work on living a calling via goal setting (95\% CI: [0.02, 0.09]), perseverance (95\% CI: [0.03, 0.14]), and learning from mistakes (95\% CI: [0.02, 0.09]), with the exception of decision making (95\% CI: $[-0.01,0.09])$. The direct path from growth mindset about work to living a calling also reached significance (95\% CI: $[0.11,0.24])$ even after including the indirect effects of the three selfregulatory strategies, thus confirming that the relationship between growth mindset and living a calling was partially mediated by self-regulation, providing support for Hypothesis 4.

\section{Discussion}

Following the SOMA model, which is congruent with selfregulation theory ${ }^{80}$ and cognitive control theory, ${ }^{81}$ the current study examined a new concept of growth mindset about work and its association with self-regulation, and living a calling among teachers, in order to characterize more precisely how a growth mindset is related to calling. Specifically, we hypothesized that self-regulation mediated the effect of a growth mindset about work on living a calling. Consistent with our assumptions, a growth mindset about work was positively associated with selfregulation and living a calling. In addition, our findings confirmed the theorizing that self-regulatory processes mediated the link between a growth mindset about work and living a calling, supporting the assumption of SOMA model. Individuals who firmly believe a successful career is developable are more engaged in self-regulatory behaviors to guide goal progress, which will then enhance living a calling. These results complement and extend the growth mindset theory and calling literature.

Regarding the direct effect of a growth mindset about work on living a calling, although causal inferences cannot be drawn in this study, our results demonstrated that a growth mindset about work might serve as an effective

Table 4 Bootstrapped Estimates for the Direct and Indirect Effects with 95\% Cl

\begin{tabular}{|l|l|c|c|c|c|}
\hline \multirow{2}{*}{ Effect } & \multicolumn{1}{|c|}{ Model Paths } & Estimate & \multirow{2}{*}{ SE } & \multicolumn{2}{|c|}{ 95\% Confidence Intervals } \\
\cline { 3 - 6 } & & & & Lower & Upper \\
\hline Direct & GMW $\rightarrow$ LC & 0.17 & 0.03 & 0.11 & 0.24 \\
Indirect & GMW $\rightarrow$ GA $\rightarrow$ LC & 0.05 & 0.02 & 0.02 & 0.09 \\
& GMW $\rightarrow$ Per $\rightarrow$ LC & 0.08 & 0.03 & 0.03 & 0.14 \\
& GMW $\rightarrow$ DM $\rightarrow$ LC & 0.04 & 0.03 & -0.01 & 0.09 \\
& GMW $\rightarrow$ LM $\rightarrow$ LC & 0.05 & 0.02 & 0.02 & 0.09 \\
\hline
\end{tabular}

Abbreviations: GMW, growth mindset about work; GS, goal setting; Per, perseverance; DM, decision making; LM, learning from mistakes; LC, living a calling. 
predictor of living a calling, indicating that cultivating a growth mindset about work can be a promising route to living a calling. Although scholars have traditionally presumed that individuals who are living out a felt calling tend to feel more committed to their careers and report greater job satisfaction, ${ }^{4,7}$ our results are closer to those who argue that living a calling should also be positioned as an outcome variable. Duffy et al., ${ }^{18}$ for example, suggest that living a calling may be viewed as the achievement of a meaningful, stimulating and satisfying career rather than the beginning of one.

Duffy et al. ${ }^{16}$ emphasized that the majority of people attributed the origin of their callings to a perfect fit with their jobs. This perspective suggests that individuals are unable to live out their calling when jobs or goals are not suitable and compatible with their interests or skills. Although past research showed that larger discrepancies between the current and desired states may lead to an increase in an effort toward that goal, ${ }^{82}$ our research confirmed that growth mindsets, which accurately reflect how efficacious one feels with regard to resolving obstacles and constraint related to career, may act as driving forces for narrowing the gap between having a calling and living a calling. Individuals with a growth mindset about work tend to proactively set up their goals and expectations, and express greater confidence about achieving goals and strive more to achieve them. Theory and evidence suggest that adopting a growth mindset predicts adaptive cognitive and behavioral outcomes, such as increased self-efficacy, ${ }^{83}$ and resilience, ${ }^{84}$ greater character strengths usage, and stronger striving for personal growth. ${ }^{85}$ As applied to work, individuals who endorse the nature of work as malleable and alterable may view person-job misfits, discrepancies between their current state and desired goals as opportunities for development and task mastery rather than as declaration of failure. In turn, they will implement a series of adaptive career strategies, such as expending more effort, ${ }^{86}$ engaging in career exploration and planning, ${ }^{69}$ to eliminate the discrepancies, ultimately experiencing living a calling. Therefore, our findings indicate that a growth mindset about work may function as a positive coping mechanism to help employees sustain persistence, prevent them from feeling helpless, and impel them to generate effective strategies when confronted with obstacles.

This study also sheds light on the potential mechanism that explains how a growth mindset about work influences living a calling. In line with the framework of the SOMA model, which positions the self-regulatory progress as a mediating mechanism underlying the effect of growth mindset on goal achievement, our results revealed that self-regulation in terms of goal setting, perseverance, and learning from mistakes, partially mediated the relationship between a growth mindset about work and living a calling, although decision making was not a significant mediator. Specifically, teachers exposed to the notion that a successful career can be developed are more likely to set learning goals, monitor goal progress, persist through challenges, reflect on mistakes and learn from experience, thus they are internally rather than externally motivated to maintain and perform an action to live out their calling. ${ }^{87}$ In other words, a growth mindset about work might stimulate the desire to adopt self-regulation strategies, which helps close the gap between people's perception of a calling and actually living out their calling. Our findings not only provide us with indications about the formation process of living a calling, but contribute to conducting an effective career interventions program for promoting living a calling, considering that a growth mindset can be cultivated.

\section{Theoretical Implications}

The current research has some theoretical contributions to the extant literature on growth mindsets and calling. First, our study makes an important addition to the limited set of studies on outcomes of growth mindsets. Mindset theories, also called implicit theories, are the basic beliefs that people adopt to organize their world and to guide their behavior. Although mindset theory originates from the academic context, it has been expanded to explain motivation and behavior in various social domains. ${ }^{82}$ However, few studies to date have investigated the benefits of growth mindsets in career literature. Our study indicated that a growth mindset about work is positively related to living a calling, adding to the literature on the benefits of a growth mindset. Second, our study contributes to the scant literature on antecedents of living a calling by examining the positive effect of a growth mindset about work on living a calling. Although scholars appreciate the importance of living a calling to employee behaviors and workplace outcomes, factors that predict it and methods to promote it are yet to be completely understood, especially from a personal perspective. Our findings indicate that a growth mindset about work may be a predictor of living a calling, and highlight the need to integrate growth 
mindsets into the theoretical models from calling literature. Third, the current study provides further evidence for the fit of an established model of SOMA, and supports its application for understanding the relationship between a growth mindset about work, self-regulation, and living a calling. Concretely, a growth mindset about work positively associates with learning goals, perseverance, and learning from mistakes, thereby leading to higher levels of living a calling.

\section{Practical Implications}

Our results have several practical implications for teacher career development and the quality of schooling. Although a sense of calling is common among teachers, teachers do not always fulfill their calling, due to various causes, including barriers in the workplace and limited opportunities for career advancement. As suggested from the results of this research, that a growth mindset about work is related to effective self-regulatory processes and living a calling, our findings can increase teachers' understanding about the potential benefits of a growth mindset, and also help principals recognize that fostering a growth mindset in teachers may be an important way to bring them to teaching and keep them engaged in their work. Evidence shows that a growth mindset may be primed or activated through positive cases and suggestions. Therefore, principals can incorporate a role model. Additionally, teachers can often be informed about the importance of hard work and of adopting effective selfregulatory strategies in the face of challenging circumstances. The results of the current study also uncovered an important mechanism through which a growth mindset about work influences living a calling via self-regulation. Identifying the mediating role of self-regulation will help career counselors understand their clients' goal-setting and pursuit processes, such as how they set goals, how they interpret success and failure, and what they expect from these goals. ${ }^{88}$ Of course, helping teachers shape selfregulatory behaviors is important, but validating their work experiences and acknowledging the constraints and barriers they face are also critical.

\section{Limitations and Future Directions}

The results of this study need to be considered in light of a number of limitations, many of which may be avenues for future research. First, this study was cross-sectional, thereby not only precluding any causal inferences, but limiting our understanding of whether a growth mindset yields a longterm impact on living a calling. A critical question for future research involves better understanding the causal effects of a growth mindset in career development, and if causal, how to cultivate a growth mindset to increase self-regulatory success. Future research, thus, needs to employ a longitudinal design or experimental approach to determine causal evidence for the relationship between growth mindset, self-regulation, and living a calling. Besides, this study relied on single-source self-report data, results might be influenced by the common method bias and social desirability bias. Future studies should make an effort to include more objective measures. Second, our sample might not be representative of the larger population of working adults, thereby limiting the generalizability of our results. Though living a calling is more prevalent in the educational setting, it may manifest itself differently with working populations. This may be especially true when trying to understand how a growth mindset relates to work-related well-being. Future scholars should consider replicating and extending these findings in more representative samples. Moreover, a direction for future research is to explore cultural variation in the theories of growth mindset and calling. Third, the present study focused only on the linkages between growth mindset about work, self-regulation, and living a calling. The underlying processes through which these positive effects occur need further clarification, as these relationships may be conditional. Thus, future studies should further examine how and when a growth mindset relates to living a calling and other positive outcomes. For example, approach-oriented goals seem to be intertwined with growth mindsets, therefore, should be considered as a moderating variable involved in the self-regulation model. In addition, further research is needed to assess whether interventions designed to enhance a growth mindset about work and self-regulation at work can increase the sense of living a calling.

\section{Conclusion}

Building on the work of Burnette et al. and the model of SOMA, this research examined the relationships among a growth mindset about work, self-regulation, and living a calling. Our results demonstrated that a growth mindset about work was positively related to adaptive selfregulation and living a calling. Furthermore, selfregulation partially mediated the positive relationship between a growth mindset and living a calling. The current evidence suggests that a growth mindset about work can meaningfully contribute to understanding why some people are committed to, and passionate about their career. 


\section{Ethical Approval}

This study was reviewed and approved by the Ethics Committee of Shaoxing University, China, and adhered to the Declaration of Helsinki. All subjects provided written informed consent before participation in the study.

\section{Acknowledgments}

The authors thank the study participants.

\section{Funding}

This study was supported by The Youth Fund Project of Humanities and Social Sciences Projects of the Ministry of Education, PRC (Grant No. 20YJC880129).

\section{Disclosure}

The authors report no conflicts of interest in this work.

\section{References}

1. Hirschi A, Herrmann A. Calling and career preparation: investigating developmental patterns and temporal precedence. $J$ Vocat Behav. 2013;83(1):51-60. doi:10.1016/j.jvb.2013.02.008

2. Shin JY, Kim TS, Ahn J, et al. Calling, career preparation behaviors, and meaning in life among South Korean college students. $J$ Coll Student Dev. 2018;59(6):734-748. doi:10.1353/csd.2018.0068

3. Yu G, Guan Y, Yang X, et al. Career adaptability, calling and the professional competence of social work students in China: a career construction perspective. J Vocat Behav. 2014;85(3):394-402. doi:10.1016/j.jvb.2014.09.001

4. Duffy RD, Dik BJ, Steger MF. Calling and work-related outcomes: career commitment as a mediator. J Vocat Behav. 2011;78 (2):210-218. doi:10.1016/j.jvb.2010.09.013

5. Hirschi A, Herrmann A. Vocational identity achievement as a mediator of presence of calling and life satisfaction. $J$ Career Assess. 2012;20(3):309-321. doi:10.1177/1069072711436158

6. Riasnugrahani M, Riantoputra CD, Takwin B, et al. Discerning work as a calling: the role of job crafting. Career Dev Q. 2019;67 (4):343-356. doi:10.1002/cdq.12203

7. Lee KJ. Sense of calling and career satisfaction of hotel frontline employees. Int $J$ Contemp Hosp M. 2016;28(2):346-365. doi:10.1108/ijchm-01-2014-0026

8. Creed PA, Rogers ME, Praskova A, et al. Career calling as a personal resource moderator between environmental demands and burnout in Australian junior doctors. J Career Dev. 2014;41(6):547-561. doi: $10.1177 / 0894845313520493$

9. Xie B, Xia M, Xin X, et al. Linking calling to work engagement and subjective career success: the perspective of career construction theory. J Vocat Behav. 2016;94(1):70-78. doi:10.1016/j.jvb.201 6.02.011

10. Bullough RVJ, Hallkenyon KM. On teacher hope, sense of calling, and commitment to teaching. Teach Educ Quart. 2012;39(2):7-27.

11. Zhang M, Chen G, Han M, Wang JY. Research on the influence of career calling on inclusive education teachers' work well-being: the mediating role of self-efficacy. Stud Psychol Behav. 2020;18 (2):248-254. doi:10.3969/j.issn.1672-0628.2020.02.015

12. Zhang LG, Li L, Sun YL. A study of the relationships between occupational stress career calling and occupational burnout among primary teachers. Chin J Ind Hyg Occup Dis. 2020;38(2):107-110. doi:10.3760/cma.j.issn.1001-9391.2020.02.006
13. Dobrow SR, Tosit-Kharas J. Calling: the development of a scale measure. Pers Psychol. 2011;64(4):1001-1049. doi:10.1111/j.17446570.2011.01234.x

14. Dik BJ, Duffy RD. Calling and vocation at work. Couns Psychol. 2007;37(3):424-450. doi:10.1177/0011000008316430

15. Duffy RD, Dik BJ. Research on calling: what have we learned and where are we going? J Vocat Behav. 2013;83(3):428-436. doi:10.1016/j.jvb.2013.06.006

16. Duffy RD, Autin KL. Disentangling the link between perceiving a calling and living a calling. J Couns Psychol. 2013;60 (2):219-227. doi:10.1037/a0031934

17. Duffy RD, Allan BA, Bott EM. Calling and life satisfaction among undergraduate students: investigating mediators and moderators. J Happiness Stud. 2011;13(3):469-479. doi:10.1007/s10902-0119274-6

18. Duffy RD, Allan BA, Autin KL, et al. Living a calling and work well-being: a longitudinal study. J Couns Psychol. 2014;61 (4):605-615. doi:10.1037/cou0000042

19. Duffy RD, England JW, Douglass RP, et al. Perceiving a calling and well-being: motivation and access to opportunity as moderators. J Vocat Behav. 2017;98(1):127-137. doi:10.1016/j.jvb.2016.11.003

20. Duffy RD, Bott EM, Allan BA, et al. Perceiving a calling, living a calling, and job satisfaction: testing a moderated, multiple mediator model. J Couns Psychol. 2012;59(1):50-59. doi:10.1037/a0026129

21. Hirschi A, Keller AC, Spurka DM. Living one's calling: job resources as a link between having and living a calling. $J$ Vocat Behav. 2018;106(1):1-10. doi:10.1016/j.jvb.2017.12.001

22. Duffy RD, Autin KL, Douglass RP. Examining how aspects of vocational privilege relate to living a calling. J Posit Psychol. 2015;11 (4):416-427. doi:10.1080/17439760.2015.1092570

23. Duffy RD, Autin KL, England JW, et al. Examining the effects of contextual variables on living a calling over time. $J$ Vocat Behav. 2018;107(1):141-152. doi:10.1016/j.jvb.2018.04.003

24. Douglass RP, Duffy RD, Autin KL. Living a calling, nationality, and life satisfaction. J Career Assess. 2015;24(2):253-269. doi:10.1177/ 1069072715580324

25. Duffy RD, Autin KL, Bott EM. Work volition and job satisfaction: examining the role of work meaning and person-environment fit. Career Dev Q. 2015;63(2):126-140. doi:10.1002/cdq.12009

26. Oprea B, Păduraru L, Iliescu D. Job crafting and intent to leave: the mediating role of meaningful work and engagement. J Career Dev. 2020;1-14. doi:10.1177/0894845320918666

27. Afiouni F, Karam CM. Structure, agency, and notions of career success: a process-oriented, subjectively malleable and localized approach. Career Dev Int. 2014;19(5):548-571. doi:10.1108/CDI01-2013-0007

28. Burnette JL, O’Boyle EH, VanEpps EM, et al. Mindsets matter: a meta-analytic review of implicit theories and self-regulation. Psychol Bull. 2013;139(3):655-701. doi:10.1037/a0029531

29. Dweck CS. Self-Theories: Their Role in Motivation, Personality, and Development. Hove: Psychology Press; 2000.

30. Dweck CS. Mindset: The New Psychology of Success. New York: Ballantine Books; 2006.

31. Dweck CS, Chiu C, Hong Y. Implicit theories and their role in judgments and reactions: a world from two perspectives. Psychol Inq. 1995;6(4):267-285. doi:10.1207/s15327965pli0604_1

32. Greenwald AG, Banaji MR. Implicit social cognition: attitudes, self-esteem, and stereotypes. Psychol Rev. 1995;102(1):4-27. doi:10.1037//0033-295X.102.1.4

33. Martin AJ. Implicit theories about intelligence and growth goals: exploring reciprocal relationships. Br J Educ Psychol. 2014;85 (2):207-223. doi:10.1111/bjep.12038

34. Mathur P, Jain SP, Maheswaran D. Consumers' implicit theories about personality influence their brand personality judgments. J Consum Psychol. 2012;22(4):545-557. doi:10.1016/j.jcps.2012 .01 .005 
35. Lim W, Plucker JA. Creativity through a lens of social responsibility: implicit theories of creativity with Korean samples. J Creative Behav. 2011;35(2):115-130. doi:10.1002/j.2162-6057.2001.tb01225.x

36. Dweck CS, Yeager DS. Mindsets: a view from two eras. Perspect Psychol Sci. 2019;14(3):481-496. doi:10.1177/1745691618804166

37. Hong YY, Chiu CY, Dweck CS, et al. Implicit theories, attributions, and coping: a meaning system approach. J Pers Soc Psychol. 1999;77 (3):588-599. doi:10.1037/0022-3514.77.3.588

38. Murphy MC, Dweck CS. Mindsets shape consumer behavior. $J$ Consum Psychol. 2016;26(1):127-136. doi:10.1016/j.jcps.201 5.06.005

39. Claro S, Paunesku D, Dweck CS. Growth mindset tempers the effects of poverty on academic achievement. P Nat A Sci. 2016;113 (31):8664-8668. doi:10.1073/pnas.1608207113

40. Burnette JL, Pollack JM. Implicit theories of work and job fit: implications for job and life satisfaction. Basic Appl Soc Psych. 2013;35(4):360-372. doi:10.1080/01973533.2013.803964

41. Han SJ, Stieha V. Growth mindset for human resource development: a scoping review of the literature with recommended interventions. Hum Resource Dev Rev. 2020;19(3):309-331. doi:10.1177/ 1534484320939739

42. Rawat A, Nadavulakere S. Examining the outcomes of having a calling: does context matter? J Bus Psychol. 2014;30(3):499-512. doi:10.1007/s10869-014-9378-1

43. Hall DT, Chandler DE. Psychological success: when the career is a calling. J Organ Behav. 2005;26(2):155-176. doi:10.1002/job.301

44. Duffy RD, Allan BA, Autin KL, et al. Calling and life satisfaction: it's not about having it, it's about living it. J Couns Psychol. 2013;60 (1):42-52. doi:10.1037/a0030635

45. Han SJ, Stieha V. Growth mindset for human resource development: a scoping review of the literature with recommended interventions. Hum Resour Dev Rev. 2020;19(9):1-23. doi:10.1177/1534484 320939739

46. Gregory JB, Levy PE. It's not me, it's you: a multilevel examination of variables that impact employee coaching relationships. Consult Psychol J Pract Res. 2011;63(2):67-88. doi:10.1037/a0024152

47. Yu J, McLellan R. Same mindset, different goals and motivational frameworks: profiles of mindset-based meaning systems. Contemp Educ Psychol. 2020;62:101901. doi:10.1016/j.cedpsych.2020.101901

48. Caniëls MCJ, Semeijn JH, Renders IHM. Mind the mindset! The interaction of proactive personality, transformational leadership and growth mindset for engagement at work. Career Dev Int. 2018;23 (1):48-66. doi:10.1108/cdi-11-2016-0194

49. Zeng G, Chen X, Cheung HY, et al. Teachers' growth mindset and work engagement in the Chinese educational context: well-being and perseverance of effort as mediators. Front Psychol. 2019;10:839. doi:10.3389/fpsyg.2019.00839

50. Cutumisu M. The association between feedback-seeking and performance is moderated by growth mindset in a digital assessment game. Comput Hun Behav. 2019;93:267-278. doi:10.1016/j.chb.2018.1 2.026

51. Frondozo CE, King RB, Nalipay MJN, et al. Mindsets matter for teachers, too: growth mindset about teaching ability predicts teachers' enjoyment and engagement. Curr Psychol. 2020;1:1-4. doi:10.1007/s12144-020-01008-4

52. Baumeister RF, Gailliot M, DeWall CN, et al. Self-regulation and personality: how interventions increase regulatory success, and how depletion moderates the effects of traits on behavior. J Pers. 2006;74 (6):1773-1802. doi:10.1111/j.1467-6494.2006.00428.x

53. Carver CS, Scheier MF. Control theory: a useful conceptual framework for personality-social, clinical, and health psychology. Psychol Bull. 1982;92(1):111-135. doi:10.1037/0033-2909.92.1.111

54. Wieber F, Thürmer JL, Gollwitzer PM. Collective action control by goals and plans: applying a self-regulation perspective to group performance. Am J Psychol. 2012;125(3):275-290. doi:10.5406/ amerjpsyc.125.3.0275
55. Shane J, Heckhausen J. For better or worse: young adults' opportunity beliefs and motivational self-regulation during career entry. Int $J$ Behav Dev. 2016;40(2):107-116. doi:10.1177/0165025 415589389

56. Dweck CS, Leggett EL. A social-cognitive approach to motivation and personality. Psychol Rev. 1988;95(2):256-273. doi:10.1037/ 0033-295x.95.2.256

57. Kray LJ, Haselhuhn MP. Implicit negotiation beliefs and performance: experimental and longitudinal evidence. J Pers Soc Psychol. 2007;93(1):49-64. doi:10.1037/0022-3514.93.1.49

58. Lam KKL, Zhou M. A serial mediation model testing growth mindset, life satisfaction, and perceived distress as predictors of perseverance of effort. Pers Indiv Differ. 2020;167:110262. doi:10.1016/j. paid.2020.110262

59. Doron J, Stephan Y, Boiche' J, et al. Coping with examinations: exploring relationships between students' coping strategies, implicit theories of ability, and perceived control. Br J Educ Psychol. 2009;79 (3):515-528. doi:10.1348/978185409X402580

60. Blackwell LS, Trzesniewski KH, Dweck CS. Implicit theories of intelligence predict achievement across an adolescent transition: a longitudinal study and an intervention. Child Dev. 2007;78 (1):246-263. doi:10.1111/j.1467-8624.2007.00995.x

61. Lee YH, Heeter C, Magerko B, et al. Gaming mindsets: implicit theories in serious game learning. Cyberpsych Beh Soc N. 2012;15 (4):190-194. doi:10.1089/cyber.2011.0328

62. Forsythe A, Johnson S. Thanks, but no-thanks for the feedback. Assess Eval High Educ. 2017;42(6):850-859. doi:10.1080/ 02602938.2016.1202190

63. Creed P, Buys N, Tilbury C, et al. The relationship between goal orientation and career striving in young adolescents. J Appl Soc Psychol. 2013;43(7):1480-1490. doi:10.1111/jasp.12108

64. Mansell W, Marken RS. The origins and future of control theory in psychology. Rev Gen Psychol. 2015;19(4):425-430. doi:10.1037/ gpr0000057

65. Singh R, Greenhaus JH. The relation between career decision-making strategies and person-job fit: a study of job changers. $J$ Vocat Behav. 2004;64(1):198-221. doi:10.1016/s0001-8791(03)00034-4

66. Kanar A. Employment goal commitment moderates the impact of job search goal orientation on the job search process. Career Dev Int. 2017;22(6):659-682. doi:10.1108/cdi-10-2016-0165

67. Lee H. Effects of goal relations on self-regulated learning in multiple goal pursuits: performance, the self-regulatory process, and task enjoyment. Asia Pacific Educ Rev. 2012;13(2):369-386. doi:10.1007/s12564-012-9216-y

68. Praskova A, Creed PA, Hood M. Self-regulatory processes mediating between career calling and perceived employability and life Satisfaction in emerging adults. J Career Dev. 2014;42(2):86-101. doi: $10.1177 / 0894845314541517$

69. Creed PA, Wamelink T, Hu S. Antecedents and consequences to perceived career goal-progress discrepancies. $J$ Vocat Behav. 2015;87:43-53. doi:10.1016/j.jvb.2014.12.001

70. Creed PA, Hughes T. Career development strategies as moderators between career compromise and career outcomes in emerging adults. J Career Dev. 2013;40(2):146-163. doi:10.1177/0894845312437207

71. Wilson AC, Lengua LJ, Tininenko J, et al. Physiological profiles during delay of gratification: associations with emotionality, self-regulation, and adjustment problems. J Appl Dev Psychol. 2009;30(6):780-790. doi:10.1016/j.appdev.2009.05.002

72. Feather NT. Values, valences, expectations, and actions. $J$ Soc Issues. 1992;48(2):109-124. doi:10.1111/j.1540-4560.1992.tb00887.x

73. Praskova A, Creed PA, Hood M. Self-regulatory processes mediating between career calling and perceived employability and life satisfaction in emerging adults. $J$ Career Dev. 2015;42(2):86-101. doi:10.1177/0894845314541517

74. Brislin RW. Back-translation for cross-cultural research. J Cross Cult Psychol. 1970;1(3):185-216. doi:10.1177/135910457000100301 
75. Pichardo C, Justicia F, de la Fuente J, Martínez-Vicente JM, Berbén ABG. Factor structure of the self-regulation questionnaire (SRQ) at Spanish universities. Span J Psychol. 2014;17(e62):1-8. doi:10.1017/sjp.2014.63

76. Weston R, Gore PA. A brief guide to structural equation modeling. Couns Psychol. 2006;34(5):719-751. doi:10.1177/0011000006286345

77. Hu L, Bentler PM. Cutoff criteria for fit indexes in covariance structure analysis: conventional criteria versus new alternatives. Struct Equ Modeling. 1999;6(1):1-55. doi:10.1080/10705519909540118

78. Preacher KJ, Hayes AF. Asymptotic and resampling strategies for assessing and comparing indirect effects in multiple mediator models. Behav Res Methods. 2008;40(3):879-891. doi:10.3758/BRM.40.3.879

79. Podsakoff PM, Organ DW. Self-reports in organizational research: problems and prospects. $J$ Manage. 1986;12(4):531-544. doi:10.1177/014920638601200408

80. Raabe B, Frese M, Beehr TA. Action regulation theory and career self-management. J Vocat Behav. 2007;70(2):297-311. doi:10.1016/j. jvb.2006.10.005

81. Carver CS, Scheier MF. Cybernetic control processes and the selfregulation of behavior. In: Ryan RM, editor. The Oxford Handbook of Human Motivation. Oxford Handbooks Online; 2012:28-42. doi:10.1093/oxfordhb/9780195399820.013.0003

82. Donovan JJ, Hafsteinsson LG. The impact of goal-performance discrepancies, self-efficacy, and goal orientation on upward goal revision. J Appl Soc Psychol. 2006;36(4):1046-1069. doi:10.1111/ j.0021-9029.2006.00054.x
83. Rhew E, Piro JS, Goolkasian P, et al. The effects of a growth mindset on self-efficacy and motivation. Cogent Educ. 2018;5(1):1-16. doi:10.1080/2331186x.2018.1492337

84. Maltby J, Day L, Hatcher RM, et al. Implicit theories of online trolling: evidence that attention-seeking conceptions are associated with increased psychological resilience. Br J Psychol. 2015;107 (3):448-466. doi:10.1111/bjop. 12154

85. Passmore H-A, Howell AJ, Holder MD. Positioning implicit theories of well-being within a positivity framework. J Happiness Stud. 2018;19(8):1-19. doi:10.1007/s10902-017-9934-2

86. Creed PA, Kaya M, Hood M. Vocational identity and career progress: the intervening variables of career calling and willingness to compromise. J Career Dev. 2018;47(2):1-15. doi:10.1177/ 0894845318794902

87. Tempelaar DT, Rienties B, Giesbers B, et al. The pivotal role of effort beliefs in mediating implicit theories of intelligence and achievement goals and academic motivations. Soc Psychol Educ. 2015;18 (1):101-120. doi:10.1007/s11218-014-9281-7

88. Wheeler SC, Omair A. Potential growth areas for implicit theories research. J Consum Psychol. 2016;26(1):137-141. doi:10.1016/j. jcps.2015.06.008
Psychology Research and Behavior Management

\section{Publish your work in this journal}

Psychology Research and Behavior Management is an international, peer-reviewed, open access journal focusing on the science of psychology and its application in behavior management to develop improved outcomes in the clinical, educational, sports and business arenas. Specific topics covered in the journal include: Neuroscience, memory and decision making; Behavior modification and management; Clinical

\section{Dovepress}

applications; Business and sports performance management; Social and developmental studies; Animal studies. The manuscript management system is completely online and includes a very quick and fair peer-review system, which is all easy to use. Visit http://www. dovepress.com/testimonials.php to read real quotes from published authors. 